\title{
O ESTUDO DAS TRAJETÓRIAS \\ DE VIDA COMO MÉTODO \\ DE COMPREENSÁO DA \\ FORMAÇÃO DE IDENTIDADES \\ PROFISSIONAIS DOCENTES
}

\author{
EL ESTUDIO DE LAS TRAJETORIAS DEVIDA COMO \\ MÉTODO DE COMPRENSIÓN DE LA FORMACIÓN \\ DE IDENTIDADES PROFESIONALES DOCENTES
}

\section{THE LIFE TRAJECTORY STUDY AS A METHOD OF UNDERSTANDING THE FORMATION OF TEACHING PROFESSIONAL IDENTITIES}

Maria da Conceição Silva LIMA ${ }^{1}$ Maria da Conceição Carrilho de AGUIAR ${ }^{2}$

\section{Resumo}

A partir de uma retrospectiva histórica, o presente artigo foca a apresentaçáo do método de História de Vida como via alternativa aos estudos sobre Formação Inicial e Identidade Profissional Docente, delineando suas perspectivas e restriçóes. Por fio condutor, o panorama apresentado por Josso (2004) e pelo Movimento Pedagógico que elege o estudo das narrativas de vida como elemento ímpar na compreensão do processo de identificação, aproximação/ afastamento com o magistério e de configuração da

\footnotetext{
${ }^{1}$ Doutora em Educação - Programa de Pós-graduação em Educação - Universidade de Pernambuco (UFPE), Recife, PE/Brasil. Professora Substituta do Depto de Administração e Supervisão Escolar - Centro de Educação/UFPE. email. mariacslimax@hotmail.com;

2 Pós-Doutora em Ciências da Educação - Universidade do Porto, Portugal. Professora Associada do Depto de Administração e Supervisão Escolar - Centro de Educação/UFPE e do Programa de Pós-Graduação em Educação-UFPE. Email.carrilho1513@gmail.com. 
identidade profissional docente. Como resultado, a valorizaçáo do professor e a possibilidade de se estudar a docência e a identidade profissional docente considerando as experiências pessoais e coletivas vivenciadas dentro e fora da escola, que possibilitaram a escolha e ratificaçáo do magistério, bem como, a práxis em sala de aula.

Palavras-chave: Docência. Identidade profissional. História de vida.

\section{Resumen}

A partir de una retrospectiva histórica, el presente articulo enfoca la presentación del método de Historia de Vida como vía alternativa a los estudios sobre Formación Inicial e Identidad Profesional Docente, delineando sus perspectivas y restricciones. Por hilo conductor, el panorama presentado por Josso (2004) y por el Movimiento Biografico Pedagógico que elige el estudio de las narrativas de vida como elemento impar en la comprensión del proceso de identificación, aproximación / alejamiento con el magisterio y de configuración de la identidad profesional docente. Como resultado, la valorización del profesor y la posibilidad de estudiar la docencia y la identidad profesional docente considerando las experiencias personales y colectivas vivenciadas dentro y fuera de la escuela, que posibilitar la elección y ratificación del magisterio, asi como la praxis en sala de estar clase.

Palabras clave: Docencia. Identidad profesional. Historia de vida.

\section{Abstract}

From a historical retrospective, the present article focuses on the presentation of the Life History method as an alternative way to the studies on Initial Formation and Professional Teacher Identity, outlining its perspectives and restrictions. The guiding thread is the panorama presented by Josso (2004) and by the Biographical Pedagogical Movement, which selects the study of life's narratives as an unparalleled element in understanding the process of identification, approximation / withdrawal from the teaching profession and the configuration of professional 
teacher identity. As a result, the appreciation of the teacher and the possibility of studying teaching and the professional identity of teachers, considering the personal and collective experiences lived inside and outside the school, which enabled the choice and ratification of the teaching profession, as well as praxis in the classroom. class.

KEY WORDS: Teaching. Professional identity. Life history.

\section{INTRODUÇÃO}

Desde o início da década de 90, os estudos envolvendo professores trazem consigo nova roupagem em suas abordagens, indicando uma amplitude na compreensão do trabalho docente, a partir da valorizaçáo da interface entre os saberes da Formaçáo Inicial e os saberes configurados no cotidiano das relaçóes desses sujeitos.

Tal feito é considerado um marco importante, pois, até entáo, o debate acerca da formação para o magistério não dava o devido crédito ao que ocorria em sala de aula, privilegiando o saber erudito, em que aspetos puramente conteudísticos e metodológicos, que se sobrepunham ao saber construído dentro experiência no contexto da escola. Assim, o cenário ainda se configurava elemento privilegiado da formaçáo docente a ideia de transposição didática, cujas reflexóes, subjetividades e intencionalidade política contidas na prática pedagógica eram elementos desconsiderados.

Nesse sentido, ao introduzirem outras dimensóes e alternativas de se pensar o trabalho em sala de aula, pesquisadores como Tardif (2008), Tardif e Lessard (2005), Nóvoa (1992), dentre outros, abriram um leque acerca dos elementos que envolviam o saber-fazer do magistério, elevando a figura do professor a um patamar de sujeito ativo no processo de ensino aprendizagem, selecionando, adaptando, ressignificando conceitos em sala de aula, conforme suas construçóes pessoais e coletivas. 
Dessa maneira, lançaram uma crítica direta aos reducionismos que sectarizavam saber expresso pelos docentes, antes classificados em processos mentais (mentalismos), oriundos das sinapses individuais, e/ou processos sociológicos (sociologismo) em que se eliminava a ação dos agentes, subordinando-os aos mecanismos sociais (TARDIF, 2008)

Isso implicou abordagens diferenciadas acerca de como um professor constrói sua identidade profissional, refutando a equivocada noção de que essa era coesa em suas configuraçóes. Portanto, podemos dizer que a inovação impactou diretamente na noção de construção de identidade de grupo que passou a ser tomada náo em virtude de suas continuidades, mas, sobretudo, de suas rupturas e de idiossicrasias, uma vez que congregava grupos de indivíduos de distintas trajetórias e com experiências diferenciadas.

Diante disso, a emergência por novas alternativas que entendessem esse professor também no âmbito de sua singularidade, como alguém que mantém uma estreita ligaçáo entre sua identidade pessoal e profissional foi permitindo uma reconfiguração no debate sobre a concepção e o próprio exercício do magistério.

Essa noção começou a se incorporar à maioria dos estudos envolvendo a docência e a relação desenvolvida no cerne de suas inúmeras representaçóes, acenando para ideia de que cada professor é único, e o seu contexto de vida corrobora para o entendimento diferenciado acerca da formação a qual é submetido.

Portanto, o que vemos é uma flexibilização na maneira de se entender o professor, agora tido como sujeito possuidor de inúmeras identidades sociais e pessoais, que tomam forma em sala de aula, sendo sua identidade profissional apenas uma expressão provisória e complexa de processos identificatórios ao longo do tempo, que traduzem momentaneamente esse sujeito para Si mesmo e para os Outros (DUBAR, 1991, 2005) 
E, distanciando-se da suposta estaticidade que lhe era atribuída, ao figura do professor passou ser investigada em face de suas inúmeras reconfiguraçōes, deixando nítida a linha tênue que dividia suas convicções particulares de sua práxis laboral. Tal pensamento sublinhou a presença de aspectos íntimos, trazidos das experiências individuais e que se coadunavam aos demais atributos exigidos para certificação para o magistério, criando uma representação particular acerca de quem eram e do entendimento de sua atividade profissional, conforme apontado por Tardif (2008, p.20).

Antes mesmo de ensinarem, os futuros professores vivem em salas de aula e nas escolas, e, portanto, seu futuro local de trabalho [...] ora, tal imersão é necessariamente formadora, pois leva futuros professores a adquirirem crenças, representaçóes, certezas sobre a prática do ofício de professor.

Nesse sentido, o entendimento dos processos interacionais que ocorreram antes da entrada do professor no magistério e durante a atuação profissional foram destacados, na medida em que se congregam experiências extremamente relevantes, não apenas para composição das aulas, como também, na própria compreensão que esse mestre tem acerca do seu papel social. Por consequência, a Formaçáo Inicial foi tida como mais uma etapa e não a única, sendo tâo importante como tantas outras, no bojo das experiências particulares e coletivas se possibilitam a (re)configuração da identidade profissional docente.

Em vista disso, o direcionamento para o estudo da atividade docente, tendo como estruturante as configuraçôes identitárias que permearam e permeiam a trajetória de vida dos sujeitos, trouxe nova luz às investigaçóes e humanizou uma atividade humana por natureza (NÓVOA, 1992). E, nesse contexto, o estudo das narrativas e experiências de vida revelou-se uma alternativa pertinente para o entendimento de como o professor se relaciona com o seu trabalho e com as demandas que o cerca.

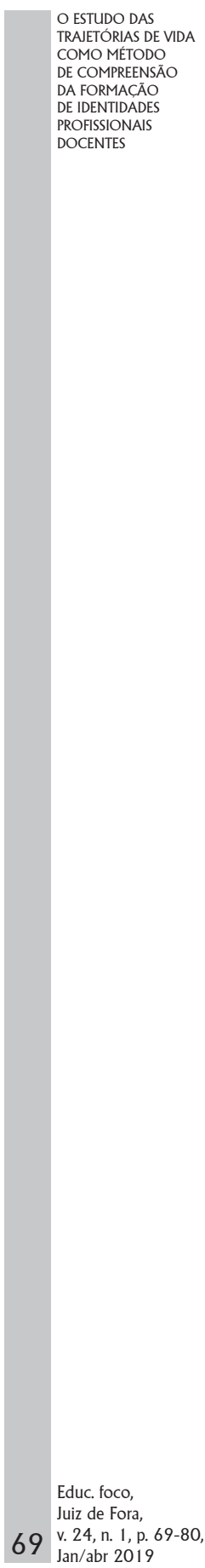




\section{Refletindo SObRe o MÉTOdo de Histórias de Vida}

Partindo da noção de que a identidade profissional contempla inúmeras mudanças ao longo das interaçôes subjetivas e objetivas do indivíduo com os outros, a ideia de se investigar com base nas experiências de vida processos que conduziram à aproximação e opção pela docência, bem como, os saberes constituídos pela prática, se mostrou uma alternativa.

A justificativa se ampara no fato do método proporcionar alto grau de singularidade no contexto de sua abordagem. Nessa direção, ele obriga o observador a apurar o seu olhar sobre o objeto, lançando-o para além do que pode ser quantificável, operando a partir de sutilezas inerentes aos processos que são individuais, ao mesmo tempo grupais, sendo para muitos, algo desafiador e que náo goza de consensos no meio acadêmico e científico.

Tal afirmação considera que o método de Histórias de Vida é, em alguns casos, alvo de depreciação por parte de outros pesquisadores que consideram "seus colegas empenhados em abordagens biográficas no campo da educaçáo, como contadores de histórias que confirmam as teses do seu quadro teórico" (JOSSO, 2004, p 172).

De acordo com Ferrarotti (1984), esse tipo de pensamento é reminiscente de uma tentativa de adaptar o método em tela ao hermetismo contido na prática tradicional. Para o autor citado, tal entendimento é deveras equivocado, pois desconhece a importância dos contributos subjetivos inerentes aos processos vivenciados, que não podem estar condicionados a uma lógica definida, positiva.

Salientamos ainda que a pesquisa envolvendo trajetórias docentes como forma de compreensão das suas identidades profissionais tem sido recorrente nos últimos anos, comprovando que a abordagem náo reside simplesmente na pura descrição de uma história, muito menos, numa mera exposiçáo do passado. Antes, porém, ela se revela 
como procedimento próprio de estudo das subjetividades inerentes às mudanças operadas nos sujeitos, a partir de suas experiências particulares, que desembocaram na constituição de suas identidades profissionais.

Estudos que desenvolveram suas pesquisas com professores a partir da análise de suas experiências de vida, a exemplo dos apresentados por como os de Pineau (1985, 1994), Nóvoa (1992), Dominicé (1996), Bueno et al (1998), Bueno (2002), e Josso (2004), contribuíram para a robustez do procedimento enquanto análise científica, dentro da perspectiva qualitativa.

Esses trabalhos confirmaram o uso das trajetórias como elemento a ser considerado, ao tratarmos da formação da identidade profissional do magistério. Como contributo maior, destacamos a percepção de como as emoçóes, as crises, as identificaçóes e os conflitos direcionam as açóes dos docentes, revelando negociaçóes nem sempre amigáveis entre as identidades individuais, sociais e profissionais, e o estabelecimento de fronteiras semipermeáveis.

$\mathrm{O}$ grande tabu talvez se concentre no fato de que o interesse pelo universo de valores individuais como mecanismo de compreensáo dos sujeitos nem sempre foi contemplado no meio acadêmico, muito tempo influenciado pelo Positivismo. Entendemos que, na medida em que a Escola Positivista passou a ser contestada com base no argumento de que as das dinâmicas sociais não poderiam ser explicadas por leis fixas e herméticas, outras áreas de conhecimento reviram seus métodos de análise investigativa, propondo outras opçóes para pesquisa.

Acerca dessa transição, a maioria dos pesquisadores aponta para a importância de um movimento surgido no interior da Universidade de Chicago, nos Estados Unidos. A Escola de Chicago, assim conhecida por desenvolver trabalhos no âmbito da Psicologia Social entre 1915 e 1940, contribuiu para o pensamento social com foco na observaçáo das práticas
O ESTUDO DAS

TRAJETÓRIAS DE VIDA

COMO MÉTODO

DE COMPREENSÃO

DA FORMAC̄ĀO

DE IDENTIDADES

PROFISSIONAIS

DOCENTES 
particulares dos sujeitos, que ganharam uma dimensão valorizada no estudo das humanidades.

Nesse contexto, destacamos os contributos de Mead (1962) e a estruturação do Interacionismo Simbólico que promoveram rupturase distanciamentos do método tradicional. Ao defender que cada sujeito fazia de maneira particular sua interpretaçáo do mundo, o autor citado considerou o papel atribuído aos símbolos sociais na construção das identidades. Ou seja, cada indivíduo exerce um olhar sobre Si com base na sua interação comunicativa com os demais. Assim, a maneira com que nos percebemos enquanto ser social está diretamente ligada a uma série de representaçóes que incorporam valores implícitos.

Daí a ideia de que os sentidos oriundos da relação entre o Eu e o Outro projetam nossa forma de ver o mundo baseada na leitura dele. Portanto, torna-se importante uma análise dos processos de socialização pretéritos, nos quais foram realizadas identificaçóes e incorporaçóes de elementos que sáo reativados no presente. Em outras palavras, houve o reconhecimento de uma individualidade na qual cada pessoa se define enquanto um sujeito e de uma identidade confeccionada a partir da relação que estabelece com o mundo exterior.

Devemos esclarecer, contudo, que os trabalhos na Escola de Chicago não se mantiveram homogêneos, ficando durante certo tempo no esquecimento, sendo retomados na década de 80 (BUENO, 2002). No entanto, o reconhecimento do sujeito como produtor de um conhecimento capaz de revelar algumas configuraçóes dos fenômenos sociais, que só encontram o seu real significado a partir do contexto que o cerca, foi basilar para os pesquisadores.

Ainda à guisa de traçarmos um percurso de reconhecimento do método aqui privilegiado, um outro movimento que contribuiu nas novas percepçóes da análise social ocorreu dentro da crítica historiográfica, e desencadeou uma série de pesquisas do que ficou conhecido nos anos 30 como Escola dos Annales. Esse movimento configurou-se 
numa tentativa de dar aos indivíduos a sua real importância na construção das relaçóes sociais, distanciando-se das análises puramente econômicas e estruturalistas que se distanciavam dos processos cotidianos mais comuns (BURKE,1991).

Elementos como a rotina, o hábito, as relaçôes familiares ganharam visibilidade. Autores como Jaques Le Goff, Peter Burke e Georges Duby contribuíram no entendimento interdisciplinar das relaçóes sociais em seus diversos mecanismos, para além do econômico. Como resultado, os documentos oficiais passaram a ser vistos como mais um elemento, e não o único, junto a outros elementos ordinários, que contribui para compreensão de contextos sociais.

Tendo por esteio os dois movimentos acima referidos, compreendemos que o campo de pesquisa tornou-se um palco de construçôes e interpretaçóes, no qual o pesquisador e o seu objeto tinham a possibilidade de interação. A vida dos personagens e suas trajetórias ganharam destaque para abordagem dos aspectos sociais enquanto fenômenos dotados de simbologia, significados e compreensão local. Dessa forma, as singularidades foram ocupando espaços antes reservado ao método hermético e experimental (BURKE,1991).

E, na medida em que foram reconhecidas as relaçôes $E$ uOutro, as repercussóes originadas dessas vivências mostraramse cada vez mais representativas na explicação do fenômeno social contemporâneo. Podemos assim considerar que a ideia de voltar o olhar para o âmbito mais intimista e relacional do $E$ u, ao tempo em que consideramos toda conjuntura cultural em que ele é formado, encontrou nessa abordagem um campo fértil para se desenvolver.

Sinalizamos também que sua relevância no campo dos estudos identitários, conforme apontou Dubar (2005), reside no fato de que ao se relatar experiências vividas ocorre uma formulação unitária de Si por parte do emissor. Assim, a identidade busca referências que a coloquem momentaneamente numa lógica linear. Ao mesmo tempo, o ato provoca no sujeito a ideia de continuidade, revelando uma
O ESTUDO DAS

TRAJETÓRIAS DE VIDA

COMO MÉTODO

DE COMPREENSÃO

DA FORMAC̄ĀO

DE IDENTIDADES

PROFISSIONAIS

DOCENTES 
identidade pessoal narrativa, a partir "dum agenciamento das suas experiências significantes” (DUBAR,2005, p 175) que são rearticuladas para expressar quem o sujeito é, e a partir de que se estrutura.

Diante dessa possibilidade de desnudar um universo de valores e açôes, mediados pela compreensão particular de cada um, as pesquisas sociais começaram a se aproximar das dimensóes mais subjetivas, e, por isso, sutis, que até então eram renegadas pelo método quantificável e tradicional. E, não demorou muito para que esse entendimento chegasse aos estudos sobre formação docente.

\section{A História de Vida na sua relação com a identidade DOCENTE}

O chamado "Movimento Pedagógico-Biográfico" foi intitulado por Josso (2004, p.85) para representar uma série de estudos envolvendo professores, realizados por pesquisadores como Dominicie (1996), Pineau (1994) e Josso (ibdem). Tais pesquisas trouxeram para o campo educacional a ideia de que as investigaçôes sobre a formação de professores "não pode limitar-se às dimensóes técnicas e tecnológicas e necessita de uma compreensão mais profunda dos processos através dos quais as pessoas se formam" (JOSSO, 2004, p.11).

Nos alinhamos a esse entendimento por creditarmos que a prática do magistério revela muito mais do que uma simples ação profissional, indicando uma forma particular de interpretação das relaçóes e estruturantes sociais que são nela articuladas (FERRAROTTI, 1984). O movimento, portanto, debruçou-se sobre a valorização de experiências formadoras, vivenciadas no lastro das trajetórias individuais, cujo entendimento revelava nuances que oportunizaram a construção da identidade profissional dos sujeitos.

Essa valorização rompeu com a hegemonia determinista e estruturalista de se analisar a formação docente, destacando a importância das experiências de vida na maneira com que esses professores encaravam sua atividade e refletiam sobre, e a partir 
dela. Tal pensamento possibilita não apenas dar visibilidade dos sujeitos envolvidos, como também, a oportunidade de contarem suas histórias e interpretaçóes, partindo das próprias perspectivas.

Ao mesmo tempo, entendemos que o método oportunizou reflexóes, produzindo um autoconhecimento, desencadeando uma maior consciência de $\mathrm{Si}$, contraposiçấo de condutas e pensamentos em diferentes sentidos (JOSSO, 2004). Além do que, acreditamos que ao se valorizar a experiência como produtora de um saber, houve um redimensionamento na valorização do profissional que passou a visualizar a atividade como um campo extensivo de suas compreensōes pessoais. E, tal como ele, estava em constante construção por intermédio das relaçóes e interpretaçôes do saber profissional (TARDIF,2008).

Depreendemos daí o entendimento de que não há uma forma determinada de ser professor, e que a relaçáo com o magistério vai se transformando, com base na interação com campo e com seus pares, produzindo formas identitárias profissionais que estão diretamente ligadas aos símbolos e representaçóes de cada contexto de labor (DUBAR, 2005).

Nesse sentido, o (re)conhecimento de Si e das ocasionais mudanças identitárias indiciam uma leitura pessoal da vida dos sujeitos e de suas açôes, numa sintonia consigo, com seus grupos de referência e com sua profissão. Isso nos permite vislumbrar esquemas, orientaçóes, tomadas de posiçáo e papéis que foram sendo desempenhados no decorrer de suas trajetórias, podendo auxiliar na compreensão da identidade profissional.

Dessa maneira, admitimos a pertinência da importância do trabalho investigativo envolvendo a História de Vida com professores, cujo corte horizontal nos permite desnudar várias facetas identitárias que se fizeram presentes no processo. Para Silva e Maia (2010), dentro da perspectiva epistêmicometodológica, um dos maiores contributos das narrativas autobiográficas reside exatamente na valorização da "dimensão
O ESTUDO DAS TRAJETÓRIAS DE VIDA COMO MÉTODO

DE COMPREENSÃO

DA FORMACCĀO

DE IDENTIDADES

PROFISSIONAIS

DOCENTES 
da experiência no contexto da vida da pessoa, tomada como objeto de conhecimento e viés de interpretação da realidade" (ibidem, p. 05).

Contudo, embora sejamos pelos motivos aqui expostos favoráveis ao estudo das trajetórias, ressaltamos que como qualquer outra tentativa de se compreender subjetividades inerentes aos processos identitários, esse método também tem suas limitaçóes, considerando a impossibilidade de analisar toda a vida de um indivíduo dentro de uma única pesquisa (JOSSO, 2004). Diante desse entrave, destacamos mais uma vez, a valorização do sujeito pesquisado, quando esse emerge como centro e articulador do conteúdo a ser analisado.

Isso se deve ao fato de que ao elencar critérios pelos quais será representada sua trajetória, ele estabelece a hierarquia, a forma de abordagem, as entonaçôes e os contextos. De acordo com Bueno (2002), cria-se uma microrrelação social que é interpretada intencionalmente pelo pesquisado e comunicada ao ouvinte, revelando um leque simbólico pessoal.

Essas memórias dão a entender quais elementos foram eleitos por ele como estruturantes, visto que, coube ao próprio pesquisado evocar suas lembranças. Cria-se assim, o quadro de recordaçóes - referência, dando uma "dimensão concreta ou visível, que apela para nossas percepçóes ou imagens sociais, e, uma dimensão invisível que apela para emoçôes, sentimentos, sentidos ou valores" (JOSSO, 2004, p.40).

Nesse contexto, entendemos que tais recordaçôes sintetizem as experiências marcantes nas trajetórias e viabilizem caminhos para pontuar evocaçóes, em virtude do significado atribuído pelo sujeito a sua formaçáo, que por sua vez, detém uma carga emocional. Para Josso (2004), essas experiências formadoras são agregadoras das aprendizagens e significaçóes, numa visão pessoal, portanto, única, dentro do sincretismo particular de cada sujeito. Entretanto, a autora também pontua que é preciso diferenciar vivências e experiências formadoras. 
Na perspectiva de Josso (2004) é importante entender a diferença entre vivência e experiência. Para autora citada, a vivência ocorre cotidianamente sem nos darmos tanta conta; em contrapartida, a experiência parte de uma vivência potencializada por ter oportunizado uma reflexão na qual a aprendizagem se constituiu, tornando-se experiência de formação. E, nesse contexto Josso (ibidem) convencionou classificá-las em três categorias: o ter a experiência, o fazer a experiência e o refletir sobre a experiência.

Entendemos que ter a experiência decorre de fatos que se mostraram significativos na trajetória, porém, não foram iniciados pelo sujeito e simplesmente ocorrem fortuitamente. No fazer experiência, subjaz um intuito pré-conclamado que possivelmente trará determinados resultados, uma vez que houve a intencionalidade de açóes e de possíveis resultados. Por fim, ao refletir sobre as experiências, levamos em conta tanto as que foram ocasionais, quanto as intencionais, relacionandoas diretamente.

Na perspectiva da História de Vida, ao fazer as conjecturas entre o ter, o fazer e $o$ refletir, os sujeitos estabelecem uma teia relacional e cheia de significados, pois é proporcionada não apenas uma evocação, como também, uma reanálise mais consciente do passado, numa perspectiva do presente, e, certamente dentro de uma projeçáo para o futuro (JOSSO, 2004). Com isso, conforme Bueno (2002, p.22), ao expor suas experiências, cada sujeito "encontra-se envolvido em uma problemática presente, mas tem uma percepção e uma visão retrospectiva de sua vida que é levada em conta quando se trata de ele próprio pensar o seu futuro ".

E, é nesse sentido que destacamos a observação de Dubar (1991, p.175) de que falar de Si para outra pessoa "é uma operação de alto risco, mesmo quando tem confiança no seu interlocutor". Ao compartilhar experiências, a identidade pessoal torna-se narrativa, exposta. E, dentro da perspectiva 
psicanalítica freudiana da qual Dubar (1991) se aproxima, a partir da explanação verbal das recordações, os sujeitos conseguem refletir, criando autonomia pessoal, embora provisoriamente, revelando possíveis contradiçôes.

A maneira como se percebem na atividade, a forma como surgiram as suas primeiras identificaçóes, os conflitos, as possíveis tensões ocasionadas na escolha, o cotidiano e as interrelaçóes dentro da escola, dentre outras coisas, formam dimensôes relevantes no processo que os conduziram e os fazem permanecer ou náo ao magistério, a partir de suas memórias e sentidos que lhe são próprios.

Assim, o método intenciona compreender o indivíduo professor por um prisma que o toma não apenas em virtude de sua atividade laboral, mas acima de tudo, numa perspectiva integradora em que suas demais identidades de pai, filho, ativista, dentre outras, possam contribuir para tecer e articular o entendimento de sua função social e do seu papel em sala de aula.

\section{CONSIDERAÇÓESS FINAIS}

Investigar o magistério e o próprio professor requer muito mais do que simples emprego de métodos a fim de obtenção de resultados. De acordo com Nóvoa (1992), a docência é a mais humana das atividades e o professor, o profissional com que mais interagimos durante nossas vidas.

Nesse sentido, compreender esse trabalho não pode se resumir a uma decodificação de suas posturas em salas de aula, como se essas se dessem a partir do nada. Existe uma pessoa, uma ideia, um propósito por trás de cada escolha, comunicação e ação que só podem ser desveladas a partir do momento em que enxergamos o docente, para além de um simples profissional que pratica atos mecânicos.

Entender situaçóes e elementos que levaram a determinadas posturas eatitudes nos ajudam a traçar de maneira mais fidedigna um contorno de quem é o professor, e como ele 
se enxerga enquanto tal. Nesse sentido, compreendemos que nenhum docente pode ser investigado apartado do contexto sócio, político, religioso e cultural do qual é oriundo, pois foi com base nesses condicionantes que suas identificaçóes os conduziram a sala de aula.

Diante disso, a relevância de maiores esclarecimentos acerca de abordagens, tal qual apresentamos aqui, se fazem cada vez mais necessárias, sob o risco de sempre unificarmos posturas, opinióes, desempenhos, tomando um grupo laboral como um todo homogêneo, cometendo o equívoco de esquecer que esse todo é formado por partes bem distintas.

\section{REFERENNCIAS}

BUENO, B. O. et al. A vida e o ofício dos professores, formaçáo contínua, autobiografia e pesquisa em colaboração. São Paulo, Escrituras Ed., 1998.

BUENO, B. O. O método autobiográfico e os estudos com histórias de vida de professores: a questão da subjetividade. Educaçáo e Pesquisa, São Paulo, v. 28, n. 1, p. 11-30, jan./ jun., 2002

BURKE, P. A Revoluçáo francesa da historiografia: a escola dos Annales (1929-1989). Trad. de Nilo Odália. São Paulo:UNESP, 1991

DOMINICE, P. L'histoire de vie comme processus de formation. Paris, L'Harmattan, 1996.

DUBAR, C. A crise das identidades: a interpretação de uma mutação Lisboa: Porto Editora, 1991.

DUBAR, C. A socializaçáo: Construção das identidades sociais e profissionais. Lisboa: Porto Editora, 2005.

TARDIF, M. Saberes docentes e formação profissional. Petrópolis: Vozes, 2008. 
TARDIF, M.; LESSARD, C. O trabalho docente: elementos para uma teoria da docência como profissão de interaçóes humanas. Petrópolis, RJ: Vozes, 2005.

FERRAROTTI, F. Une théologie pour athées. Paris, BordasDunod, 1984.

JOSSO, M. C. Experiências de vida e formaçáo. São Paulo: Cortez, 2004

MEAD, G. Mind, self and society: from the standpoint of a social behaviorism. Chicago: The University of Chicago Press, 1962 (Trabalho original publicado em 1934).

NÓVOA, A. (org.). Vidas de professores. Porto: Porto Editora, 1992.

PINEAU, G. Histoires de vie et changement paradigmatique em éducation. Rèperes, n. 05, p. 69-73.1985.

PINEAU, G. Histoires de vie et formation de formateurs. Les métiers de laformation. Paris, La documentacionfrançaise, pp 107-112, 1994.

SILVA, F. C. R.; MAIA, S. F. Narrativas Autobiográficas: interfaces com a pesquisa sobre formação de professores. In: VI ENCONTRO DE PESQUISA EMEDUCAÇÃO DA UFPI, 2010, Teresina-PI. Anais do VI Encontro de Pesquisa em Educação da UFPI, 2010. 